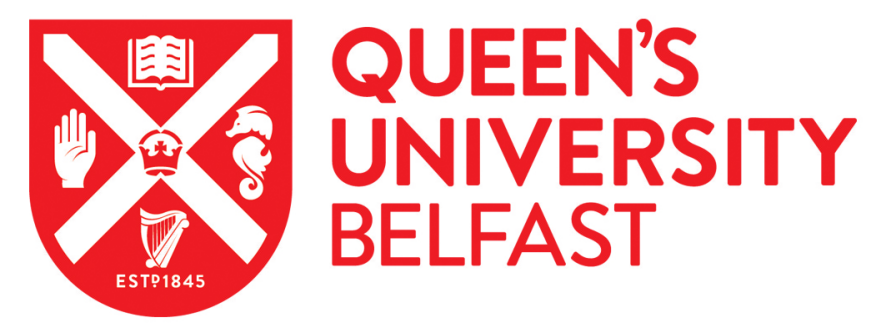

\title{
Getting In and Getting On? The Experiences of Young People with Visual Impairments and Hearing Impairments in Third-Level Education
}

Byrne, B. (2014). Getting In and Getting On? The Experiences of Young People with Visual Impairments and Hearing Impairments in Third-Level Education. International Journal of Disability, Development and Education, 61(2), 119-133. https://doi.org/10.1080/1034912X.2014.905057

Published in:

International Journal of Disability, Development and Education

Document Version:

Peer reviewed version

Queen's University Belfast - Research Portal:

Link to publication record in Queen's University Belfast Research Portal

Publisher rights

(C) 2014 Taylor \& Francis

This is an Accepted Manuscript of an article published by Taylor \& Francis in International Journal of Disability, Development and Education on 09 May 2014, available online: http://wwww.tandfonline.com/10.1080/1034912X.2014.905057

\section{General rights}

Copyright for the publications made accessible via the Queen's University Belfast Research Portal is retained by the author(s) and / or other copyright owners and it is a condition of accessing these publications that users recognise and abide by the legal requirements associated with these rights.

Take down policy

The Research Portal is Queen's institutional repository that provides access to Queen's research output. Every effort has been made to ensure that content in the Research Portal does not infringe any person's rights, or applicable UK laws. If you discover content in the Research Portal that you believe breaches copyright or violates any law, please contact openaccess@qub.ac.uk. 
Getting In and Getting On?

Getting In and Getting On? The Experiences of Young People with Visual Impairments and Hearing Impairments in Third-Level Education

\section{Bronagh Byrne}

Byrne, B. (2014) 'Getting In and Getting On? The Experiences of

Young People with Visual Impairments and Hearing Impairments in Third-level Education', International Journal of Disability, Development and Education, 61(2) 119-133

DOI: 10.1080/1034912X.2014.905057 


\title{
Getting In and Getting On?
}

\begin{abstract}
Young disabled people continue to be under-represented throughout further and higher education settings. Drawing on Pierre Bourdieu's social theory of habitus, capital and field, this paper explores the practices of domination and oppression which have made it difficult for young people with visual impairments and hearing impairments from participating in thirdlevel education on the same basis as non-disabled people. Twenty young people with hearing impairments and visual impairments were interviewed about their educational experiences. In addition, thirty-one interviews were conducted with third-level education providers, policymakers and non-governmental organisations. This paper has two aims. Firstly, to critically examine the experiences of young people with hearing impairments and visual impairments in accessing and engaging with support provisions in further and higher education settings; and secondly, to identify and explore the diversity of ways in which these young people have managed and responded to the practices they have encountered. This paper emphasises the journey form ability to dis-ability that young people with hearing and visual impairments experience in their quest for educational achievement. The ambiguities of 'inclusion', 'widening participation' and 'support' are highlighted and critiqued for their extensive failure to challenge taken for granted discourses.
\end{abstract}

\section{Keywords}

Visual Impairment, Hearing Impairment, Further Education, Higher Education, Support, Inclusion 


\section{Getting In and Getting On?}

\section{Introduction}

The recognition of education as a necessary staple of contemporary society is undeniable. What is disputed is the key domain wherein the benefits and goals of education lie. It is perhaps somewhat naïve to seek a single answer to this posed dilemma since education can be understood to have a range of economic, social, cultural and affective outcomes (see for example, Baker et al (2004); Chitty (2004); Crawford (2003); Lynch and Baker (2005); Riddell et al (2005)). Whilst the role of education as a means to personal development and individual capacity building for all remains central, the economic goals of education have been given renewed emphasis in the context of globalisation and 'late modernity' (Beck 1992). This has been particularly so with respect to post-compulsory or third level education (Bowl 2012). The meritocratic expansion of education in this way has not been without criticism, with the move towards marketisation being described as 'corrosive to the social relationships of curricular justice’ (Nunan et al 2005: 253).

Concern has thus shifted to extending access and participation in third level education to previously under-represented groups in a bid to reconcile the gap between the 'learning rich' and the 'learning poor’ (Tuckett and Aldridge 2010). Discourses of widening participation and inclusion have been resonant in both further and higher education settings (Riddell et al 2005; Thomas 2001; Blythman and Orr 2002; Hayton and Paczuska 2002; Bowl 2012). However, it also continues to be an arena in which young disabled people are significantly underrepresented. Whilst achievement and progression is designated as important for all, provision for young disabled people has been arguably negatively skewed towards the lower end of the non-academic spectrum in a way that has been pejorative to their moral worth and social inclusion. This is in spite of the seemingly embracing language of 'inclusion' that has gained 


\section{Getting In and Getting On?}

common currency in contemporary society. How concepts such as 'widening participation', ‘inclusion' and 'support' are operationalised and normalised by educational institutions plays a key role in determining the extent to which cultural processes and deeper social structures, which have marginalised disabled people, are effectively challenged. It is these taken for granted practices of institutional and systemic discrimination (McLaughlin et al 2006), or 'routine regimes of social action' (Cassin 2006) which are at the centre of this paper.

Drawing on Pierre Bourdieu's social theory of habitus, capital and field, this paper explores the practices of domination and oppression which have made it difficult for young people with visual impairments and hearing impairments to enter and progress within further and higher education settings on the same basis as non-disabled people. It draws on a Northern Ireland study in which twenty young people with hearing impairments and visual impairments were interviewed about their educational experiences in further and higher education. In addition, thirty-one interviews were conducted with third-level education providers across further education (hereafter, College A and College B) and higher education (hereafter, University A and University B), policymakers and non-governmental organisations. ${ }^{1}$ This paper has two aims. Firstly, to critically examine the experiences of young people with hearing impairments and visual impairments in accessing and engaging with support provisions in further and higher education settings; and secondly, to identify and explore the diversity of ways in which young people with hearing and visual impairments have managed and responded to the practices they have encountered. In so doing, this paper emphasises the journey from ability to dis-ability that young people with hearing and visual impairments experience in their quest for educational achievement. It argues that this journey is predicated on a socially constructed ability binary which locates 'ability' in the minds and bodies of a non-disabled majority and which designates

\footnotetext{
${ }^{1}$ Pseudonyms are used throughout.
} 


\section{Getting In and Getting On?}

particular skills and characteristics as 'meritorious' and others as undesirable. The paper concludes by suggesting that whilst there has been some progress in making third level education more accessible and inclusive of those with sensory impairments, much remains to be done lest designated 'support' provisions themselves unwittingly become part of the structures of domination and oppression that perpetuate social divisions and forms of educational exclusion.

\section{A Bourdieudian Framework}

Disability has been a classic field in which the excesses of determinism on the one hand and excessive individualism on the other have been evident at various times and in various works. Nowhere is this more evident than in the longstanding distinction that is made between the individual/medical model of disability and the social model of disability. While disability has been reconceptualised as a function of the structures and institutions inherent in contemporary society, the social model fails to take sufficient account of either cultural or impairment effects and their subsequent interaction (Shakespeare 2013). It could be further argued that the social model has failed to effectively uncover the dialectic between structure, culture and agency in a way that adequately reflects the complexity of disabled people's lived experiences. Within an individualist viewpoint, for example, there is a danger of attributing everything to the power of agency, including the experience of disability within third-level settings. By adopting a reductionist approach, individual or agential explanations of structure and society elevates the causal role of actors, and fails to account for the potential or real role of government who initiate (ex)(in)clusive policies; educational institutions who implement policies; inaccessibility and discrimination; and inadequate and inappropriate staff levels, training and resources. Once more, the 'problem' of disability, and subsequent experiences, become located with the 'impaired' individual. Conversely however, young disabled people are not merely 


\section{Getting In and Getting On?}

robots or puppets on a string. They are not 'powerless victims', but young adults with developing identities and some degree of self-determination. Structural approaches in their various forms, however, omit the extent to which young people may choose to accept or challenge those expectations or constraints with which they are faced, or in choosing between educational courses, locations, and 'support' available. As Corker and Shakespeare have argued, "The global experience of disabled people is too complex to be rendered within one unitary model or set of ideas” (Corker and Shakespeare 2002: 15).

The intricacy of the interrelations between agency, structure and culture has been imaginatively presented by Pierre Bourdieu in his many works. Pragmatically forged out of empirical research and confrontations with opposing viewpoints, Bourdieu explores the ways in which both subjective and objective structural and cultural resources, processes and institutions maintain individuals and groups in competitive and self-perpetuating hierarchies of domination and oppression. Bourdieu's theory of practice connects action to culture, structure and power. Practices are neither purely objectively determined, that is, a consequence of social structure; nor are they purely the product of free will, that is, of individual agency. It is this dialectical relationship which has remained largely elusive in the disability field (but see Ridell et al, 2005). Edwards and Imrie (2003) have explicitly argued for the inclusion of Bourdieudian concepts in the search for a disability theory and, in so doing extend the application of the sociological imagination (Mills 1959) to the field of disability. They critique the reductive nature of both the medical and social models of disability and suggest that "Both conceptions, while capturing aspects of people's lives, are problematical for failing to recognize that there is a dialectical relationship between the individual and society, or where intersubjective and subjective experiences are intertwined” (Edwards and Imrie 2003: 240). By locating young 


\section{Getting In and Getting On?}

people’s educational experiences within a Bourdieudian framework, this paper also seeks to contribute to that dialectical endeavour.

At the core of Bourdieu's attempts to overcome theoretical reductionism are the concepts of 'habitus', 'capital' and 'field'. Together these constitute Bourdieu's theory of practice. This theory of practice is central to the exploration of the dialectic between objectivity and subjectivity; the individual and society (Bourdieu 1977). According to Bourdieu, action is not merely a mechanical response to objective structures but is mediated by the habitus, the field and the availability of forms of capital. The Bourdieudian juxtaposition of objectivity and subjectivity can be expressed in the following way:

$$
[(\text { habitus })(\text { capital })]+\text { field }=\text { practice }
$$

(Bourdieu 1984: 101)

Within the context of this paper, the formula can be illustrated more specifically:

[(habitus of disability) (capital)] + field of learning = the practices of disability

The habitus of disability can be understood as the "product of the internalization of the structures of the social world" (Bourdieu 1989: 18). As both structuring and structured, the habitus of disability can be transmitted by experiences, processes and institutions, but can in itself generate thoughts and action. While action may have the appearance of rational behaviour, this is in effect guided by a 'feel for the game'. Hence, the apparent 'rationality' of young disabled people in 'choosing' between educational options, courses or location is unconsciously guided by that 'feel for the game' and the associated internalisation of social 


\section{Getting In and Getting On?}

structures. The dispositions inculcated within the habitus leads to the individual 'knowing one's place' (Bourdieu 1990a, 1990b, 2000), and the 'others' place, that is, the place of the non-disabled majority, and which can be maintained by processes of misrecognition:

The sense of one's place is a practical sense..., a practical knowledge that does not know itself, a 'learned ignorance'... which, as such, may be the victim of that particular form of misrecognition (allodoxia), consisting in mistakenly recognizing oneself in a particular form of representation and public enunciation of the doxa. The knowledge supplied by incorporation of the necessity of the social world, especially in the form of the sense of limits is quite real, like the submission which it implies and which is sometimes expressed in the imperative statements of resignation: 'That's not for us'...(Bourdieu 2000: 185)

For this reason, a young person who is deaf or blind may approach third-level education with caution, perceiving it as 'not for the likes of us'. Such perceptions can be continually reinforced by outside agents such as teachers, parents and wider cultural assumptions as well as institutional discourses of disability and (in)equality. Understandings about ways of 'being' and 'doing' and related social divisions become 'naturalised' and enable the 'familiar' world or 'cultural arbitrary' to be taken for granted (Bourdieu 1990b). It is this 'naturalisation' which emerges as part of those ‘deeper structures' of domination and oppression.

The habitus of disability is mediated by the accumulation, possession and convertibility of various forms of 'capital'. The forms of 'capital' to which Bourdieu refers are resources upon which individuals and groups draw and utilise in order to maintain or enhance their (involuntarily ascribed) positions in the social order. Capital is "what makes the games of society...something other than simple games of chance...” (Bourdieu 1986: 241). These resources include economic capital, cultural capital, and social capital. Together these forms of capital constitute the network of power relations. Forms of cultural capital include educational qualifications, cultural goods and services, and awareness and access to information. Perhaps most importantly for the young people in this study, is the inclusion of 


\section{Getting In and Getting On?}

linguistic forms of capital, that is, those presupposed and naturalised forms of written and spoken competences demanded by the cultural arbitrary, and which make it difficult for some young people with disabilities to fully participate in the field of learning on an equal basis with their non-disabled peers. This is especially relevant when analysing the educational experiences of those young deaf people who are sign language users and whose linguistic difference makes capital accumulation and conversion problematic. The remainder of this paper identifies some key themes that emerged for the young people in the study.

\section{The Bane of Further Education: Discrete Provision}

Discrete provision has been an unstinting feature of further education for young disabled people. While some forms of discrete provision in further education remain for people with severe learning disabilities, and particular educational settings for those who are deaf and/or visually impaired, a rhetoric of inclusion and mainstreaming has significantly reduced such provision. However, it was clear from the study that some young people with visual and hearing impairments were being subject to inappropriate educational provision on the basis of implied inability rather than choice.

Sophie is a visually impaired young person, employed as an administrator in a statutory body. She is a Braille user and requires JAWS screen reading software. After completing a BTEC in Business and Finance at a college for visually impaired students in England, Sophie returned to Northern Ireland where she decided to undertake further training in IT. Sophie eventually decided to enrol in College B on a part-time IT course following a positive meeting with the college’s Learning Support services. The practices she encountered, however, were far from perfect: 


\section{Getting In and Getting On?}

It was horrendous. I went there and every week the Braille was wrong for the work, they put me in a class full of people with severe learning disabilities....I asked [to move to another course] but I was told I couldn't be moved because it was a few weeks into the course and they couldn't move me. The equipment that they gave me every week had something wrong with it. It never worked. I always reported it and it was never fixed. I would come in the next week and nothing was done. They kept making excuses like; 'it is the students that are doing this to the computer'. So it was just excuse after excuse.. I would never go back to [College]. I would never recommend it to anyone at all. It was horrible. (Sophie)

Upon completion of the course, Sophie achieved a 'distinction'. She attributed this to the combination of her own ability, the basic nature of the course and the computer skills she had already accumulated. Sophie strongly felt that 'If I had of (sic) went in [at] any higher [level], I wouldn't have passed it because I didn't get the equipment to do the course, I didn't get the support...I got nothing'. Sophie was not told until her first day at college that the course she was encouraged to enrol on was a form of discrete provision catering specifically for young people with severe learning disabilities. Sophie does not have a learning disability.

Sophie's involuntary segregation from mainstream provision is not only an example of discriminatory practice, but an explication of the ability binary which continues to locate ability and merit within the minds and bodies of the non-disabled majority. This was in spite of the College's overall commitment to 'inclusive learning', and its status as an award winner for the quality of such provision. While the achievement of such an award is no mean feat and must not be underestimated, this arbitrary designation reinforces legitimation of particular forms of support which are then held up as 'best practice'. 'Best practice', however, remains grounded in getting 'around' and 'overcoming barriers', and the perceived 'ability' of the young person to 'cope' with course demands. Even though the College stated that 'We have

some [discrete] classes which are for people with special needs....people with profound disabilities...', in practice the distinction between the types of 'disabilities' or impairment necessitating discrete provision is less clear. The need for students to be able to 'cope' in a 


\section{Getting In and Getting On?}

mainstream environment by virtue of individualised forms of support is another example of less explicit cultural coding that reinforces the naturalisation of a non-disabled world. This was unwittingly illustrated by College B who stated that their general objective was to 'assess people to see what help they need to survive in mainstream...our main thrust is to try and help people survive in the 'big world' with everyone else' (emphasis added). Another young person, Patrick, described how he had been enrolled on a further education course in England which catered primarily for people with learning disabilities rather than deaf people. Both Sophie and Patrick's experiences illustrate the ways in which institutional discourses of disability and emergent practices continue to dis-able young people’s abilities on the grounds of impairment.

\section{Conflicting Practices of Disability 'Support'}

Most young people felt that their experience of (mainstream) further or higher education was 'ok'. Some were genuinely impressed with the level of support provided, while others were critical of the pressures that had been borne on them by virtue of requiring support. There was however, a general trend of misrecognition across the sample of what constituted 'normal' practice.

Facilitating the Support Choices of Students

All institutional respondents highlighted, in principle at least, the importance of 'student choice’ in assessing support requirements. For example:

It is very important to listen to the student because they know their own disability and they know their own support. I think in general, in disability it can be very dangerous to think that all students with one disability have the same requirements. Every student has different support and support needs (University A) 


\section{Getting In and Getting On?}

It does vary on need...Its very individual (College B)

The focus that remains on assessing 'the kind of difficulties people have with all aspects of teaching and learning...'(University B) indicates an implicit assessment of the extent to which people with visual and/or hearing impairments are perceived to deviate from cultural 'norms' and practices. The burden of change thus appears to fall on the individual. This individualisation of support facilitates avoidance or denial (Cohen 2001) of the need for institutional change and perpetuates invisibility of institutional causes of inequality and exclusion. Concerns were frequently raised throughout the institutional sample about whether or not a visually or hearing impaired student would be able to adapt to the requirements or demands of a course. College A suggested that the extent to which a student would succeed on a course would depend, in part, on the student's ability to 'cope' and 'the extent of the impairment and how the student overcame [their impairment]'. The same college also defensively suggested that 'There are barriers, but they are not barriers set by the Institute; they are barriers that are part and parcel of trying to get..., accurate advice and guidance to a student' (College A).

Whilst some form of support may be required on the basis of individual need, too much emphasis on this succeeds only in further legitimating rather than challenging dominant pedagogies. This is not to deny that pockets of good practice exist and continue to be developed. University A appeared to have made the most progress in seeking to challenge taken for granted pedagogies and described how they were attempting to mainstream disability across teaching and learning. One recent initiative was the appointment of 'Disability Advisers’ within each university school and faculty. Each Adviser was a member of school staff, ranging from lecturer to professor, who had responsibility for disability issues. It was felt 


\section{Getting In and Getting On?}

that this had been pivotal both in raising awareness of disability issues more generally among academic staff, and in enhancing the quality of support that the student received.

The extent to which University B was making substantive progress was less clear. One senior manager in University B stated that:

I believe [Disability Services] is working very well. The reason why I say I believe it is working very well is because I don't get any complaints anymore. So I assume. (University B)

Service evaluation based on a lack of complaints is not a reliable indicator of good practice. Some young people may not feel able to challenge any issues that arise. Kelly for example highlighted how during one class, she became so frustrated at not being able to follow class dictation that she went home early. She did not raise this issue with staff until over a week after the incident. Another student, Cheryl, relied on speech software but found that the package installed on the university computers was '... not very up to date.' While Cheryl felt that the software could 'probably' be updated if she asked, she had yet to do this and did not appear comfortable with doing so. College A justified the lack of requests from students for more extensive support such as interpreters or specialist software packages in the following way:

I think [students] are not challenging us in a way to do that [provide other support] (College A)

Thus, a certain onus is placed on students to ensure that support provision concurs with need. Both Orlaith and Rufus felt that it was each student's responsibility to ensure they received good quality support otherwise this would not be forthcoming:

It is up to you to do it. It is your personal responsibility to request those things. I know you can access it and get those things done for you, but you have to request it first yourself... You have to know what you need before you need it and you have to 


\section{Getting In and Getting On?}

know it is available before you need it but it is not made aware to you that it is available. It is quite awkward and it is a vicious circle. (Orlaith)

I am the type of person who if I did need a requirement or if I had a problem I would just say to them... It was up to me to actually go up to them and say 'look I need' [W] hen they were handing out handouts and I couldn't see the print on them it was then up to me to go and say 'is there any chance of getting this enlarged because I have a visual impairment?’ and none of them had a problem doing it. (Rufus)

Yet Rufus, like other students, continued to misrecognise the practice of providing (and receiving) support, which 'naturally' took longer to facilitate than day-to-day materials for non-disabled students:

There was maybe the odd time that there was a delay in getting things like an enlarged paper but you are talking about a day or two. I understood that because they did have to go and make a special copy for you. Or maybe they had to go back to the document that they printed it off and had to increase the size and all with the print and change the diagrams and then print it out on different pages. But I took that into consideration. It was never a problem. (Rufus)

Practices such as these experienced by Rufus and others accords priority to the legitimate and familiar needs of a non-disabled majority in contrast to the singular needs of a few.

Forms of Support: Choosing to go without

The experience of visually impaired and hearing impaired students across third-level suggests that a substantive gap between policy and practice remains. Forms of support can in fact become part of, and exacerbate, structures of domination and oppression, and experienced as disabling rather than enabling. Receipt of Disabled Student's Allowance within higher education posed particular difficulties for some of the young people. The trend towards 'direct payment' of Disabled Student's Allowance to the individual, who then purchases the services or equipment required, is intended (like Direct Payments more generally) to foster a culture of independence and empowerment (Barnes et al 1999; Riddell et el 2005). This suggestion is at odds with the perceptions of those young people in this study who were responsible for paying 


\section{Getting In and Getting On?}

and organising their support. Helen, a deaf law student at University A, used a speedtext operator for classes that were particularly difficult to follow. Helen received her Disabled Student Allowance directly and was responsible for ensuring the speedtext operator was paid on time:

I thought that [paperwork] was a bit of a nightmare. How long [speedtext operator] stayed and all this...the money aspect and trying to remember how long she stayed that day or if she came in that morning? But I only had her [for] a couple of mornings... but if I had to do that for every single one of my lectures it would have been a nightmare. (Helen)

Helen was aware that the responsibility of completing paperwork was not something that was bestowed on the rest of her classmates. This became a burden and she was glad that she did not have this support for all of her classes. Attempts to enhance young people's autonomy through the direct payment of support can become a double-edged sword. Both Helen and Gareth felt that this practice should have remained within the remit of Disability Services.

Gareth, also a hearing impaired student at University A had a similar experience:

What I found was that the support the university offered was more of a hassle than just turning up and trying to get on with it. I had lived with this ...suddenly I had a note-taker, which in itself wasn't a problem but then I also had to fill in loads of forms. I had to meet with the people in the disability centre... I also had to meet regularly with the note-taker and fill in a time sheet for them and then apply for funding from the local education authority and then pay them as I was their employer. But of course there were no instructions then in relation to if I am their employer what do I do about tax and National Insurance. I had no idea but I felt initially, by the way it was presented, that I was responsible. All of that was hard work. In the meantime I was trying to get on with my reading and doing my studying and writing my essays and so on and so forth. I just thought 'this is ridiculous'... If this is support I felt more disadvantaged with all of that than I did living with my disability.... It is just like, 'no, if I come to you for help then help me don't just burden me with a load of more paperwork'. That was more of a problem actually than my hearing. You know, dealing with all that. And there is something wrong with that when the support you try to get is more stressful than actually living with what it is you are living with. (Gareth) 


\section{Getting In and Getting On?}

Gareth experienced the individualised nature of support he received as oppressive. He resented the feeling of responsibility that was conferred on him and felt that he should have been able to 'get on with' completing assignments. The practice of completing forms and liaising with Disability Services conflicted with Gareth's sense of self, and made him more aware of his disadvantaged position in the social order; something he had not previously considered to any great extent. It is through interaction with Disability Services that Gareth's feelings of difference come to the fore; 'Why do I suddenly feel different now that I have asked for support?’ The experiences of students like Gareth and Helen converge with the Bourdieudian dictum that any substantive reduction in educational inequalities (whether implicit or explicit) will require fundamental institutional change at deeper levels.

The Conflict between Forms of Support and Embodied Dispositions

The desire to ‘fit in’ and self-distance from individualised conceptualisations of disability came across strongly. This desire emerged from a perception that they did not already 'fit in' or that they felt 'out of place' due to the visibility of their impairment or particular forms of support. For young deaf people, the visibility of hearing aids and/or notetakers or speedtext operators was highlighted as frustrating. Embodied dispositions, constitutive of young people’s habitus of disability, played a key role in mediating young people's responses to various forms of support.

It was clear that some of the young people in the study sought to orient practices towards "the maximisation of ....symbolic profit” or capital (Bourdieu 1980: 209) by 'managing' or resisting the type of support they received. Both Anne and Helen used a speedtext operator throughout their respective courses in Psychology and Law. Yet this appeared to replace one 'problem' with another: 


\section{Getting In and Getting On?}

Sometimes it is very hard to make friends because with speedtext, it is very close to the front, and everybody sits away at the back so it is a bit hard at times (Anne)

Even though Anne was now able to understand her lectures better than previously, the act of sitting at the front of the class with her (elder) speedtext operator, while everyone else sat at the back, became 'embarrassing'. Anne did not have many friends on her course and felt isolated. Thus, the act of receiving support becomes, on the one hand, a functional solution to an otherwise inaccessible situation, and on the other, a form of negative symbolic capital and social segregation. Helen had a similar experience:

In first year I had the other [analogue] hearing aids and I couldn't hear with them very well at all so I got the woman to type for me. I found it embarrassing sitting in the front and having her sitting beside me so everyone knew then and it was a massive room. And she always came in late and made such a big racket getting into the lecture and everybody would have looked [at her] and then looked at me, and it was more like a big sign pointing to me saying 'oh you are deaf and everybody knows'. It was sort of embarrassing and then when I got the new [digital] hearing aids I was glad then. I could just go to the lectures like everybody else and sit anywhere in the room and not have to sit down at the front. So that is what I noticed the most. (Helen)

After Helen received her digital hearing aids, she felt she no longer required speedtext and now she now relied solely on hearing aids and lipreading. While forms of support such as speedtext have been successful in enabling pedagogic access for many young deaf people, focus remains on the young person's perceived 'inability' to readily participate and not on the arbitrariness of perceived competences or pedagogies. The examples of Helen and Anne further illustrate the ways in which objective conditions can become inscribed in young people's habitus of disability, and become manifest in day-to-day practices. The adoption of speedtext exacerbated Helen and Anne's feelings of difference and acted as a 'marker' or 'a big sign' (Helen) of what they saw as their disadvantaged position in the social hierarchy. 


\section{Getting In and Getting On?}

Helen and Lauren spoke of how they were able to disguise their hearing aids by wearing their hair down, while Anne preferred not to wear hearing aids at all. Marks (1999) has suggested that this practice of 'hiding disability' is not new. Rather, the body becomes a form of symbolic value or 'status'. The desire to be like non-disabled peers is "the effect of a power, which is durably inscribed in the bodies of the dominated, in the form of schemes of perception and domination” (Bourdieu 2000: 171). Inscribed in these schemes of perception and domination, and which became manifest in practices more generally, is the association of impairment with disability along with a need to compensate for individual deficit by adopting strategies of 'passing'.

Despite digital hearing aids, Helen continued to have difficulty in tutorials and was unable to follow the flow of the discussion. She also had problems in one of her lectures as the lecturer spoke too quietly and had an unfamiliar accent. Helen felt that attending these lectures was a 'waste of time' and chose not to attend, relying on her friends for notes. While Helen recognised this was a problem she felt additional support would not be beneficial:

If I wanted, I probably could get people to come, you know a person to come with me to my tutorials, I would like that but it is like making a statement and everybody just seems to look at them and you know...? (Helen)

Such embodied dispositions illustrate the dialectical relationship between 'impairment' and 'disability' that continues to exist, and which cannot be as easily separated as the social/medical model binary would imply. The young people were in effect responding to their 'feel for the 'game’’ (Bourdieu 1990a), on the basis that the 'game' in the subfield of thirdlevel education, works best for those who are able to conform to the norms of a societal majority, that is, upon practices of 'passing'.

\section{The Role of Support Workers}




\section{Getting In and Getting On?}

Most of the young people in my study required some form of 'human assistance' such as an interpreter, notetaker or personal assistant. The quality of support workers was a recurring theme across both student and institutional interviews. The importance of choosing the 'right' support worker was highlighted across third-level settings. One of the key dilemmas for Disability and Learning Support Services in universities and colleges was finding a support worker who was relatively close in age to the student, and who would empower rather than disempower the student. The young people in the study had varied experiences of support workers. The importance of finding a 'good match' between student and support worker was reflected in the experience of David who had a visual impairment:

I have a personal assistant who... is funded for thirty-two hours a week. That is including my class times and then any extra work that I need to do after that they will fund that as well. But he works as a support worker, a notetaker and he also helps me with my research in terms of coming down to the library with me and getting books out and looking at them for me... One thing that I liked was; he does have a background in computers. That is one thing that [Disability Services] do where possible; [they] would make a requirement [that the student has background knowledge in the subject]. So he has supported me in a subject that he is aware of and we are not in the situation where he is not able to follow the class himself. It is basically a simple case of if you don't understand the subject yourself then how are you going to support somebody else in turn. (David)

David's assistant was only a few years older than him. This was in contrast to David's previous experience at College B where the support workers had little direct experience of his course of study:

There was one time when... the speech wasn't working on my computer and I was trying to find out why it wasn't working so I said to [support worker] 'are we on the Windows desktop?' She looked at me and said 'what is a desktop?'...So only because I had visual memory of using it, I was able to explain to her and say 'does it look like this here?' ....you know, I am sitting in an advanced IT class with somebody who doesn't know what a desktop is! Looking back you are sort of going, how does this person really explain anything then on an excel worksheet or anything like that, or if we were doing some advanced formulas or something, how is she going 


\section{Getting In and Getting On?}

to help? She was an extreme case. (David)

The boundary between fostering a culture of independence and dependence is clearly an important one. The negotiation of boundaries was often tricky and depended on both the disabled student's habitus of disability and that of the support worker. Mismatch between each party's habitus of disability was common, and this often led to feelings of frustration on the part of the young person receiving the support

Young deaf people also found accessing fully qualified sign language interpreters more difficult than anticipated. A number of young people expressed discontent and disappointment at the relatively low quality of interpreting they received. This impacted upon subsequent practices. Kayleigh outlined the difficulties she encountered:

When I went to [College B]... I didn't know who the interpreter was and the problem was that some of them were quite good and some of them weren't... I thought I was only going to get qualified interpreters and it was a bit of a shock to get what I got. Whenever I signed the way I signed the interpreter would say 'oh no Kayleigh, you can't sign like that, slow down'. And they found it difficult to cope with me so I had to really restrict myself in the way that I expressed myself to be able let them understand me. Then the interpreters changed around an awful lot, which is very difficult. (Kayleigh)

Even though sign language was Kayleigh's first language, she was unable to express herself in the way she was used to. Kayleigh was shocked to discover that not all interpreters were fully qualified or fluent in her preferred language. The use of less than fully qualified interpreters is due, in part, to the lack of interpreters in Northern Ireland more generally. The difficulty in accessing fully qualified interpreters also resulted from the policy of College B who employed and trained their own support workers and interpreters. Students were not able to choose their preferred interpreter or ensure that interpreters had been trained to particular standards. This practice fails to fully recognise the grammatical complexity of sign language in comparison to 


\section{Getting In and Getting On?}

the spoken word. This lack of respect and recognition further demeans the validity of sign language as expressed by young people like Kayleigh, and locates students in positions of dependence. Kayleigh described how she would have preferred to have another interpreter who knew her relatively well and with whom she would have been able to express herself naturally. Since this person was not employed by the College, Kayleigh had to accept an interpreter who was unable to 'cope’ with her fluency. The turnaround of interpreters meant that Kayleigh had to learn to adapt to different styles and levels of qualification; something her non-disabled peers did not have worry about.

Another student at College B, Beth, was impressed with the extent of provision she received when she was required to attend external seminars. However, the quality of the interpreting was less impressive and Beth became discontent. Overcoming this issue was made more difficult by her close relationship to both interpreters:

I ha[ve] two interpreters every week and on a personal level I'm good friends with them. But on a professional level one is very good. I had her three years ago and she was nervous when she started working with me because of the content of the course. What I was doing was quite intense. She didn’t feel competent enough to interpret for me. I encouraged her just to give herself a go. She tried and continued, this is our third year together, and she is improving all the time. She is very good with the voice over. The second interpreter is just lovely. She interprets for me every Thursday when I am doing chemistry and biology which is quite intense. Her language skills would not be of a high standard even though she is a hearing person. She left school when she was fourteen or fifteen. So when I want to ask [the lecturer] a question I would rely on [the interpreter's] voiceover and when she uses her voiceover I recognise the lack of strength in her vocabulary and I am concerned that when she voices for me that other hearing people would think that the level of language that I use was limited. I feel that she needs further training with regards to her language skills. In that respect I am not too happy about it...I find when I want to ask a question I speak for myself now because of the way she speaks for me. [It's] very frustrating that I can't rely on her to represent me well. (Beth emphasis added)

Beth was concerned that others' perception of her ability would be influenced by the quality of interpreting. This is an interesting example of the ways in which aspects of a support worker's identity such as social class, can transfer to the support receiver, and perpetuate negative 


\section{Getting In and Getting On?}

conceptions of ability. It is interesting to note that Beth herself perceives hearing people as possessing greater language skills by virtue of spoken English. Beth no longer felt comfortable with expressing herself in sign language and increasingly tried to use her voice to participate in class. This placed Beth under considerable pressure. Even though interpreters are available, the converse privilege of the non-disabled majority continues to be reproduced. Beth was also concerned about the standard of interpreters across the college:

So far [the college] have five interpreters... Two of the interpreters I wasn't pleased by any means to have them because they are rubbish at interpreting. They are very patronising. They baby the [deaf students], which to me is an insult to our intelligence. (Beth)

Beth did not feel able to effectively challenge the quality of provision due to already established college policy. The direct management of support workers by College B can be understood as a form of symbolic violence through which some sign language users can feel obliged to succumb to the linguistic discourse of the majority culture in a bid to succeed.

\section{Conclusion}

The emergence of progress across third level settings has not gone unnoticed. Initiatives such as disability advisers in education settings, learning support provisions such as standardised and accessible exam papers and the plethora of 'new builds' incorporating the latest technology, are examples of good practices which are beginning to emerge and which are encouraging to see. The data discussed in this paper however, suggests that the experiential reality of third-level education continues to be characterised by complex forms and practices of discrimination. Educational inequalities are not only manifest in their immediate consequences but extensively contribute to feelings of powerlessness and inadequacy. The reactive nature of disability disclosure policies place considerable pressure upon students to 


\section{Getting In and Getting On?}

define and categorise themselves as inherently 'different' at a time when 'fitting in' is perceived by young people as crucial to positive experiences in the educational domain. Young people with hearing and visual impairments are therefore less able to embrace an individualised 'choice identity’ (Beck 1992) than their non-disabled peers.

Increases in disability support provision are widely perceived to be 'a good thing' or an indicator of institutional commitment more generally. Yet individualised and needs-based assessment and support continue to be portrayed as a 'gift' or 'concession' rather than a fundamental human right. Forms of support as objectified by disability services or learning support can in and of themselves become 'carriers' and perpetrators of 'disablism' (Thomas 1999: 48). Supports which claim to facilitate inclusion must therefore be regarded with caution. Areas of provision which require the individual student to adjust and fit in with existing practices have exacerbated deeper and less visible patterns of inequality. Emphasis remains on the difficulties young people with hearing and/or visual impairments have with legitimised practices of teaching and learning and not on the difficulties that emanate directly from the construction and naturalisation of such practices, It is clear that such support provision can be experienced as an instrument of communication, cognition and mode of distinction between the dominant and dominated (Bourdieu 1977), facilitating a proverbial 'paradox' of support and contributing to the constructed negative existential status of disability and processes of 'othering'

Moreover, little or no attempt is made to challenge the assumptions of familiarity and arbitrary notions of 'ability' on which third level education is based. Thus young disabled people, particularly those who are blind or sign language users, are unable to participate on their own terms. Discourses of widening participation, inclusion, and support can thus be understood as 


\section{Getting In and Getting On?}

objectifications of dominant world visions. These discourses are much less challenging than they might initially appear and become manifest as strategies of conservation rather than subversion of existing practices. Whilst heightening the need for change, these discourses remain encroached in 'safe' change in ways that are favourable to the cultural arbitrary and remain insensitive to young people's habitus of disability and dispositions to choose. This form of domination becomes self-perpetuating and may create new patterns of participation by accepting only those disabled people who have 'right' kinds of capital and are able to successfully become 'one of us' by conforming to meritocratic ideals. Concepts of inclusion and equality as currently operationalised, may instead signify the appearance of "sympathetic participation and enthusiastic proximity” (Bourdieu 1990: 3). Unless the dialectic relationship between structure, culture and agency are adequately recognised and challenged, practices of widening participation, inclusion and support will continue to be grounded in the rules of a non-disabled arbitrary for whom the phrase 'Welcome into $\underline{\mathbf{m y}}$ world' is intransigent. 


\section{Getting In and Getting On?}

\section{References}

Baker, J., Lynch, K., Cantillion, S. and Walsh, J. (2004) Equality: From Theory to Action, Hampshire: Palgrave Macmillan

Barnes, C., Mercer, G. and Shakespeare, T. (1999) Exploring Disability: A Sociological Introduction, Oxford: Polity Press

Beck, U. (1992) Risk Society: towards a new modernity, London: Sage.

Blythman, M. and Orr, S. (2002) ‘A Framework for Institutional Change’ in A. Hayton and A. Paczuska, Access, Participation and Higher Education: Policy and Practice, London: Kogan Page

Bourdieu, P. (1977) Outline of a theory of practice, Cambridge: Cambridge University Press.

Bourdieu, P. (1984) Distinction: a social critique of the judgement of taste, Cambridge: Harvard University Press.

Bourdieu, P. (1986) 'Forms of Capital' in J.C. Richardson (ed) Handbook of Theory and Research for the Sociology of Education pp.241-258. Reprinted in S. Ball (ed.) (2004) The Routledge Falmer Reader in Sociology of Education, London: Routledge Falmer.

Bourdieu, P. (1989) Social Space and Symbolic Power in Sociological Theory, Vol. 7: pp.1425.

Bourdieu, P. (1990a) In Other Words, Cambridge: Polity Press.

Bourdieu, P. (1990b) The Logic of Practice, Cambridge: Polity Press.

Bourdieu, P. (2000) Pascalian Mediations, Cambridge: Polity Press

Bowl, M. (2012) Post-compulsory, higher education and training, in J.Arthur, A. Peterson, The Routledge Companion to Education. Routledge: London, pp199-208

Cassin, M (2006) Routine Regimes: Systemic Discrimination, Inequality and Privilege, Paper presented at Equality and Social Inclusion Conference, Belfast: February 2006. 


\section{Getting In and Getting On?}

Chitty, C. (2004) Education Policy in Britain, Hampshire: Palgrave Macmillan.

Cohen, S. (2001) States of Denial, Cambridge: Polity Press.

Corker, M. and Shakespeare, T. (2002) Disability/Postmodernity, London: Continuum.

Crawford. K. (2003) Contemporary issues in Education: An introduction, Norfolk: Peter Francis Publishers.

Edwards, C. and Imrie, R. (2003) Disability and Bodies as Bearers of Value in Sociology, Vol. 37 No. 2: pp.239-256.

Hayton, A. and Paczuska, A. (eds.) (2002) Access, Participation and Higher Education: Policy and Practice, London: Kogan Page.

Lynch, K. and Baker, J. (2005) 'Equality in Education: An Equality of Condition perspective' Theory and Research in Education, Vol. 3 No. 2: pp.131-164.

McLaughlin, E., Khaoury, R. and Cassin, M. (2006) Complex Forms of Discrimination, Equality and Social Inclusion in Ireland Project: Working Paper 45.

Marks, D. (1999) Disability: Controversial Debates and Psychosocial Perspectives, London: Routledge.

Mills, C. Wright (1959) The Sociological Imagination, New York: Oxford.

Nunan, T., George, R. and McCausland, H. (2005) 'Inclusive Education in Universities: Why it is important and how it might be achieved' in K. Topping and S. Maloney (eds.) The Routledge Falmer Reader in Inclusive Education, Oxon: Routledge/Falmer.

Riddell, S., Tinklin, T. and Wilson, A. (2005a) Disabled Students in Higher Education: Perspectives on widening access and changing policy, London: Routledge.

Shakespeare, T. (2013) Disability Rights and Wrongs Revisited. $2^{\text {nd }}$ ed. London: Routledge.

Thomas, L. (2001) Widening Participation in Post-Compulsory Education, London: Continuum. 


\section{Getting In and Getting On?}

Thomas, C. (1999) Female Forms: Experiencing and Understanding Disability, Buckingham: University Press.

Tuckett, F. And Aldridge A. (2010) A Change for the Better, NIACE 